\title{
Museus, Memórias e Narrativas
}

\author{
Jamile Borges da Silva'
}

\begin{abstract}
Resumo:
O objetivo desse texto é proceder a uma reflexão sobre o papel da memória na (re)constituição das identidades coletivas e as consequências das disputas pela memória em sociedades pós-coloniais. Isso significa entender como os registros memoriais e documentais nos museus digitais tem estimulado novas discussões nos campos da antropologia, museologia e história.
\end{abstract}

Palavras-chave:

Museus; Memória; África

\begin{abstract}
The purpose of this text is to reflect about the memory in the (re ) creation of collective identities and the consequences of struggles for memory in postcolonial societies. It means understanding how the memories and documentary records in digital museum has stimulated new discussions in the fields of anthropology, museology and history.
\end{abstract}

\section{Keywords:}

Museum; Memory;Africa

II de Dezembro de 1958. Guiné-Bissau. Chegada de uma delegação militar, chefiada pelo Subsecretário de Estado do Exército, Francisco da Costa Gomes, numa missão «de carácter militar, mas relacionada com diversos aspectos económicos locais, e com a localização de aquartelamentos militares no interior da Província». Julho de 1959. Costa Gomes volta a passar por Bissau «a fim de estudar assuntos relacionados com actividades do Comando Militar» e previne o então Governador Peixoto Correia sobre as informações de que «estava em preparação, uma revolta dos homens que faziam o serviço do porto, cargas e descargas, que eram manjacos». 03 de agosto de 1959. Marinheiros de Bissau desencadeiam um movimento grevista, com a participação de capitães, contramestres, marinheiros e cozinheiros, reivindicando aumentos de salários (invocando a dureza das condições de trabalho e o custo da aliาmentação arroz, azeite de palma e «casseque», ou seja, peixe-seco). A maioria, da etnia dos manjacos, era quem fazia o trabalho de estiva.

Os «Capitães» convocaram uma concentração para as três horas da tarde no cais do porto, a fim de devolverem os barcos e recusarem terminantemente retomar o trabalho enquanto os salários não fossem aumentados. Cerca das quatro da tarde, o chefe Conceição «dirigiu-se ao porto e foi dar ordens aos marinheiros para continuarem a trabalhar e como eles nem sequer se mexeram dali, começou a empurrá-los e até chegou a dar uma bofetada a um deles»; os marítimos ripostaram violentamente, brandindo os remos, paus, barras de ferro e arpões com que se haviam armado.

I Profa.Adjunta da UFBA. Dra. em Estudos Étnicos e Africanos. Antropóloga. Coorda. Do Museu AfroDigital da UFBA. http://www.museuafrodigital.ufba.br 
Ouviram-se os primeiros tiros (para o ar), houve luta pelo domínio das armas e várias agressões, começando a correr sangue. Imediatamente foram chamados reforços policiais para a zona do cais, que assumiram posição de combate (diz o testemunho de um dos «guardas» que «o tenente Simão foi logo à esquadra onde organizou o pessoal para o Pindjiguiti porque estava a haver guerra com os marinheiros»). Generalizou-se a insurreição, foi dada ordem de «fogo!» pelo comandante militar, tenente-coronel Filipe Rodrigues (para outros, a ordem veio do tenente Simão). Foram cinco minutos de tiroteio e lançamento de granadas, com perseguição aos grevistas que tentavam fugir na direcção do cais e abrir os portões, entretanto encerrados. No fim, há uns 13 a 15 mortos espalhados no cais do Pindjiguiti; muito mais cadáveres de marítimos e estivadores são arrastados pelas águas do Geba, não se sabe quantos; alguns moribundos ou gravemente feridos vão falecer no hospital [...]. ${ }^{2}$

O episódio descrito acima é considerado um marco fundamental na história do PAIGC e para a luta de libertação nacional em Guiné e Cabo Verde. Tendo estado em Bissau algumas vezes desde 2010 e ouvido relatos orais, assistido documentários produzidos pela rede de televisão portuguesa (RTP) ${ }^{3}$ e lido alguns artigos sobre esta tragédia, resolvi tomá-lo como mote para fazer as seguintes interrogações: como reconstruir o imaginário de uma época ou de um episódio? O que pode/deve ser tomado em consideração? Quais são os critérios historiográficos, antropológicos ou mesmo literários para essa análise?

Qual o papel da memória na (re)constituição das identidades coletivas e as consequências das disputas pela memória em sociedades pós-coloniais ? Como entender a política de sentidos e a polifonia implicada nos registros memoriais e documentais sem deslizar para leituras hegemônicas ancoradas nas práticas da colonialidade do saber /poder, conforme teoriza Quijano (2005) ? Ou ainda, enquanto intelectuais, como promover a emergência de uma nova geração de pesquisadores preparados teórica e metodologicamente para empreender novos 'dispositivos' políticos, discursivos e tecnológicos sobre os processos sociais de memória?

Como ler politicamente o que aconteceu na noite de 03 de agosto 1959? Parafraseando Guimarães (20I5) a sobrevivência da memória (assim como a das imagens) não diz respeito apenas a sua vida póstuma, mas se endereça ao nosso presente, visado pelo passado e continuarão a nos assombrar no futuro.

O objetivo deste texto é, portanto, longe de esgotar a reflexão sobre as interfaces entre memória, politica, antropologia e fazer historiográfico, propor ferramentas analíticas para compreender a 'disputa pela memória" nos museus digitais e como a história e o passado de populações subalternizadas vêm sendo musealizados, expografados, reivindicados, patrimonializados, servindo de arena de luta política e cultural.

Segundo a socióloga argentina, Elizabeth Jelin ${ }^{4}$ (2002), responsável por coordenar o projeto sobre as memórias da repressão naquele país precisamos falar de 'memórias'(no plural), compreendidas como uma construção discursiva,

2 Cfr. Joaquim Areal, «Crónica da Província», in BCGP, n. ${ }^{\circ}$ 53, pp. 125 e segs In: SILVA, Antonio E. Duarte. Guiné-Bissau: a causa do nacionalismo e a fundação do PAIGC. Cad. De Estudos Africanos, Lisboa, 2006. 3 A GUERRA. Série produzida por Joaquim Furtado para a RTP. Disponível no endereço: http://www.rtp. pt/programa/tv/p26314.

4 Pesquisadora e diretora académica do Programa Memoria Colectiva y Represion, BA/Argentina, apoiado pelo Social Science Research Council (SSRC) para o Cone Sul. 
perfuradas em sua rede, cheias de lacunas, rasuras e omissões resultantes das condições sócio-políticas, tornando a narrativa - a maneira através da qual o sujeito constrói um sentido do passado- uma memória que se expressa em uma história, transmissível com um mínimo de coerência.

\begin{abstract}
Em primeiro lugar, é preciso entender as memórias como processos subjetivos, ancoradas em experiências e marcas simbólicas e materiais. Em segundo lugar, reconhecer memórias como um objeto de disputas, conflitos e lutas, que visa prestar atenção para o papel ativo e produtor de sentido, marcados por relações de poder. Terceiro, historicizar as memórias, isto é, reconhecer que existem mudanças históricas no sentido do passado, assim como no lugar atribuído às memórias em diferentes sociedades, clima, espaços culturais, de lutas políticas e ideológicas. (2002:27)
\end{abstract}

O debate ora proposto se organiza em três esferas:a) a discussão acerca da relação entre museu e memória b) a interface entre museus, tecnologias digitais e antropologia e c) a tensão entre os museus do futuro ou o futuro dos museus, lembrando com certa ironia uma velha máxima de Adorno que, em 1953, num ensaio sobre Valéry, Proust e os museus dizia: a felicidade da contemplação não pode prescindir dos museus.

Museus, Memórias e Narrativas

Vivendo como hedonistas num tempo em que ficamos conectados em rede com e sem fio quase obsessivamente - Era de Extremos, Tempos Interessantes, nas palavras do falecido escritor marxista Eric Hobsbawn - cabe a nós, como pesquisadores interessados no difícil trabalho de organizar a memória social e coletiva, perguntar, assim como o faz Menezes (1998): uma vez superado o dilema entre relíquia (objeto histórico) versus artefato (objeto atravessado pela teia de relações simbólicas internas e externas ao museu), interrogar: que alternativa cabe a esses lugares de memória, aos museus, e, acrescento: o que cabe aos museus digitais enquanto lugares para a reinvenção das narrativas sobre as memórias e seus representantes digitais ?

Abandonando a noção de senso comum que define museu como conjunto de coleções delimitadas e hierarquizadas para a ideia de um espaço impreciso e complexo, atravessado por múltiplos agenciamentos e dispositivos (Guattari, 1992) me interessa refletir sobre as disputas por memória encarnadas nas novas políticas patrimoniais que vem se desenrolando em todo o mundo, sobretudo, a partir das noções de doação digital, copyright, copyleft, estímulo à criação de incontáveis plataformas de museus digitais que supõem, como nos lembra E. Glissant, uma outra poética para lidar com uma nova politica arquivística e discursiva em nome da memória e do patrimônio da humanidade.

Sair das velhas práticas canônicas de exposições coloniais, de coleta através de espólio, roubos, expropriação da produção cultural de diferentes grupos para chegar ao que se postula hoje na perspectiva de uma nova museologia social de "coleta do presente" é um desafio que se põe a todos que estão envolvidos com a área da patrimonialização e da cultura, especialmente em sociedades pós-coloniais e pós-independência.

A nova museologia social tem argumentado em favor da afirmação dos museus como lugares para que se proponham outras estratégias de preserva- 
ção, representação, conservação e exposição dos artefatos e seus representantes digitais. Mais que isso, que sejam lugares para a crítica a esses mesmos artefatos e ao discurso produzido sobre eles.

Não é novidade que os museus são herdeiros da prática de sequestro dos antigos tesouros, das catedrais e dos palácios, e ainda, dos gabinetes de curiosidades. É fato conhecido também que todos os impérios coloniais durante seu projeto de expansão e domínio produziram barbárie, causaram, em muitos casos, genocídios (Congo, Haiti,Argélia,Abissínia, Etiópia, etc.) e promoveram saques, roubos e destruição de arte, bens culturais, livros, assim como promoveu o epistemicídio de distintos grupos étnicos. Inúmeros objetos foram pilhados pelas várias expedições de Marcel Griaule e Henri Labouret na África, por exemplo, e que resultaram no grandioso acervo do Musée de l'Homme em Paris, causando o apagamento de traços e vestígios da história desses povos. Aliás, Walter Benjamin chega a afirmar que "não existe um documento da cultura que não seja, ao mesmo tempo, um documento da barbárie".

O roubo despudorado de objetos - no caso dos países africanos a ênfase em elementos exóticos que demarcavam o lugar do Outro, diferente, bestializado, desalmado-, funcionou muito bem alimentando a tensão etnológica entre natureza e cultura, civilizados e selvagens, colonizadores e colonizados, o que ajudou a construir alguns dos mitos fundadores da antropologia.

Após anos de missões etnográficas, viagens patrocinadas por impérios coloniais, museus reconstruídos e memórias reabilitadas - por exemplo, a devolução dos restos mortais de Saartje Baartman ${ }^{5}$ feita por Nelson Mandela inúmeras questões se colocam em perspectiva: a quem pertencem os objetos, artefatos e coleções expostos nos museus espalhados ao redor do mundo? $O$ que pode ser caracterizado como patrimônio "da humanidade"? O que fazer com os constantes pedidos de repatriação de restos mortais que estão nos acervos dos museus? O que significa hoje em dia falar de autenticidade e direito à propriedade sobre as peças, fragmentos, narrativas e representações da alteridade traduzidos pelos objetos nestas instituições?

Os já conhecidos e sofisticados museus históricos, coloniais ou mesmo alguns museus contemporâneos, ainda retratam a complicada condição de um espaço fechado onde, segundo Certeau (20II), se efetuam duas operações de sentido contrário: o esquecimento, que, longe de ser um fenômeno passivo, é um dispositivo de luta contra o passado, e o vestígio, que é o retorno do esquecido, ou seja, uma ação desse passado daqui em diante forçado ao disfarce. $O$ passado, como o fantasma de Hamlet, assombra o presente. A história é "canibal".

Talvez, uma atitude mais radical e emancipadora seja, em lugar dos constantes exercícios epistemológicos e metodológicos para interrogar o passado de dentro dos museus, a de refletir sobre a nossa relação com a coleta do presente, suas contradições e descontinuidades, promovendo o inventário dos lugares, numa estratégia geopolítica mais condizente com uma atitude crítica em relação ao nosso papel como intelectuais na produção e representação da memória individual e coletiva. Admitindo, portanto, que mais importante que o acontecimento em si, é sua construção no tempo, a supressão e o ressurgimento de suas significações, seus usos e abusos.

5 Depois do fim do "apartheid" em 1991, uma das primeiras reivindicações da etnia khoi-khoi a Nelson Mandela foi o regresso à África do Sul dos restos mortais de Saartje Baartman. O presidente sul-africano falou do assunto, em 1994, com o então presidente francês François Mitterrand que se opôs às reivindicações sul-africanas usando o argumento da "inalienabilidade das coleções nacionais. Em 2004, entretanto, o parlamento acabou por aprovar a devolução da Vénus hotentote como ficou conhecida. 
Incendiar os Museus?

Em maio de 68 na França, o movimento estudantil levantava a bandeira "Incendiar o Louvre" porque entendia que os museus eram espaços de reprodução dos valores da burguesia.

Em 2003, Julian Spalding ex-diretor dos museus e galerias de Glasgow, fez uma provocação ao que ele considerava um 'projeto canônico' adotado pelos museus dizendo: Museums are in the internet business. Our job is to generate interes. Em outras palavras, o museu deveria deixar de ser um depósito de coisas e se tornar um negócio, induzir o consumo e gerar interesse.

Para Menezes (2000) é nessa mesma linha de showbusiness e servindo à lógica do mercado, que vão surgir as chamadas blockbusters exhibitions, as exposições 'arrasa-quarteirões', que, naturalmente, procuram legitimar-se com a aura da "cultura".

Estou convicta de que, no século $\mathrm{XXI}$, os museus não podem ser espaços anacrônicos e nostálgicos, receosos de se contaminarem com o vírus da sociedade contemporânea - modelos como os Museus Comunitários/ neighbourhood museums a exemplo do Anacostia em Washington, até os chamados eco-museus trouxeram notável renovação no campo geral da museologia - antes, poderão se constituir como extraordinárias vias de conhecimento e exame dessa mesma sociedade.

Conforme Scheiner, a modernidade tardia permitiu pensar o patrimônio como espaço de articulação entre as pequenas singularidades (indivíduos, culturas locais e vizinhança) e as instâncias de representação articuladas sob a forma de organismos oficiais como os Museus.

(...) Hoje, as tecnologias digitais apontam para novas e inusitadas relações e o patrimônio adere ao tempo do digital como representação simbólica de diferentes grupos sociais. (2009 : 48).

Nos séculos $X X$ e $X X I$, o Brasil se torna pródigo em institucionalizar a memória através da criação de museus para celebrar o patrimônio nacional. Para Cunha ${ }^{6}$ isso pode ser explicado, no caso brasileiro, em virtude da necessidade de (re)construção de imaginários que justificassem a nação. Como nos lembra Lilia Schwarcz:

(...) os Institutos Geográficos e Históricos, as Escolas de Direito e de Medicina, bem como os Museus, se afirmaram como espaços em que o perfil ideal do Brasil e do Homem Brasileiro era estudado, forjado e apresentado ao público." (2006 : 33)

$\mathrm{Na}$ esteira desse mesmo argumento, Tota vai dizer que na sociedade contemporânea, os museus são:

um armazém de memória onde se traçam as identidades étnicas e onde as classificações históricas e naturais inscrevem e reescrevem o passado e o presente das nações. (2000: 123).

Bem verdade que o termo Museu, nos dias de hoje, vem sendo utilizado

6 CUNHA, Marcelo Nascimento Bernardo da. Teatros de Memórias, Palcos de Esquecimentos: Culturas africanas e das diásporas negras em exposições museológicas. PUC. São Paulo. Tese. 2006 , p. 285 
de modo indiscriminado ${ }^{7}$ para representar/significar elementos de um conjunto disforme, confuso e heterogêneo formado por milhares de instituições espalhadas mundo afora. Em geral, não possuem acervos próprios, não contam com um corpo técnico de profissionais, tampouco têm acompanhado ou refletido acerca dos grandes temas e demandas da museologia contemporânea.

A perspectiva conservadora e canônica de Museu que separa público e acervos como entidades separadas por vitrines de vidro tende cada vez mais a se dissolver. Para romper este abismo entre o público e as coleções, será preciso induzir, produzir formas diferenciadas de ações e políticas patrimoniais e museais recorrendo, sobretudo, às inovações tecnológicas, sem perder de vista a função social, histórica e política dos museus.

Já se disse que o Brasil é um país sem memória e que os museus não têm futuro garantido dado os parcos investimentos no âmbito das políticas públicas, ainda que esse cenário venha gradativamente se modificando nos últimos anos como podemos ver nos dados do Instituto Brasileiro de Museus -IBRAM ${ }^{8}$ sinalizando que existem hoje no Brasil mais de 2.600 museus mapeados e cadastrados.

O dado que nos chama atenção é de que o levantamento revelou que, dos museus mapeados, apenas 29 estão cadastrados como museus virtuais. Em 2008 eram 18, incluindo o museu da corrupção e o museu do sexo.

De uma coisa já podemos ter clareza: um paradoxo se instala no campo das políticas patrimoniais, sobretudo em países como o Brasil com tradição de pouca memória e baixo investimento em cultura: a proliferação de museus de toda ordem (Museu da Pessoa, Museu do futebol, Museu das minas, Ecomuseus, Museu do Amanhã, etc. ) coloca em xeque o questionamento sobre sua função de "guardião do passado", posto que, em muitos desses museus, celebra-se uma espécie de presente continuum, cuja função parece ser mesmo a celebração de nosso cotidiano como memória do porvir. Museus criados politicamente pensando no amanhã, no efeito da ressonância política nas gerações futuras.

Nunca se criou tantos museus físicos, de pedra e cal, como o que se vê hoje em todo o mundo, especialmente no Brasil da era das ações afirmativas. O que torna essa reflexão ainda mais interessante em virtude da relação ainda problemática entre custos, investimento público, ausência de uma política patrimonial clara no âmbito federal e baixo investimento em manutenção e conservação dos equipamentos museais já existentes e consolidados.

Ademais, podemos encontrar também diferenciados suportes digitais, agrupados sob a incerta definição sociológica de "redes sociais" que se prestam - ou se autorizam - ao trabalho de criar projetos e performances tratados como dispositivos expográficos com intenção de ser uma espécie de "Museu de Tudo" na Internet, a saber FLICKR? , Facebook e o mais recente grande "case

7 Tome-se como exemplo $O$ Museu da Inocência saído das páginas de um livro para um endereço real. O Museu da Inocência é certamente inusitado é dá título ao livro escrito pelo turco Orhan Pamuk (vencedor do Prêmio Nobel da Literatura em 2006). A história se passa na Turquia dos anos 1970 e conta a história de Kemal, homem comprometido de 30 anos que se apaixona pela jovem Fusun e que depois de um affair desenvolve uma obsessão pela jovem. Daí, seu protagonista organiza um melancólico museu de objetos que remetem à imagem da sua amada. Ali constam relógios, televisores, colheres, roupas e outros pequenos objetos do período em que se passa a história e que fazem parte também do acervo do museu da vida real, localizado perto da praça Tazkim, região onde se desenrola a história, e inaugurado pelo autor em abril de 2012 .

8 Para mais informações acesse http://museus.cultura.gov.br/ IBRAM

9 Flickr é um site de compartilhamento de imagens, lançado em 2004 e comprado pela empresa Yahoo! no ano seguinte. $O$ site tem hoje mais de 7 bilhões de fotos publicadas. A conta gratuita no Flickr permite envio de 300 MB de fotos e vídeos por mês. Até mesmo o recém criado Museu de Arte do Rio (MAR), já 
de mídia", conhecido como Pinterest ${ }^{10}$. Esse crescimento exponencial de ambientes para gerir, organizar e socializar fotografias e estimular um colecionismo digital nos dá uma mostra da difícil e problemática relação que a nossa geração tenta manter com o passado e a tentativa desesperada de guardar $\circ$ presente em pixels e bytes para as gerações futuras.

A despeito das correntes mais engajadas no campo da Nova Museologia e das ferrenhas críticas ao conceito de museu 'moderno' - isto é, produzido dentro da temporalidade histórica da modernidade - aquele que aprendemos na escola, é inegável que os museus ainda são entendidos como expressões da memória nacional. Nesse sentido, essa explosão museal - físico ou digital - tende a reforçar a ideia de museu como guardião da tradição e da memória nacionais. Heloisa B. de Holanda, em pequeno texto publicado em sua página na Internet no ano de 2012, nos advertia sobre a estreita vinculação entre a criação dos museus e a ordem simbólica das sociedades modernas, o que nos leva a compreender o fato de que os museus, na realidade, se constituíram como um efeito da modernização e de seu compromisso teleológico, ou seja, de seu compromisso com o futuro e não com o passado ou com a tradição. Não é, portanto, a manutenção da tradição que marca a origem dos museus, mas, ao contrário, a ameaça de sua perda, aliada ao desejo de reconstruí-la.

As narrativas contemporâneas no campo da sociologia da comunicação apontam para o fato de que estamos vivendo a "era da obsolescência planejada", isto é, os objetos e artefatos são feitos para desaparecer. Como entender então essa recente obsessão pela musealização de todas as coisas?

É nesse cenário que se reconfiguram os museus digitais, seus espaços, sua nova territorialidade, virtualidade e interatividade, suas políticas e práticas enquanto expressão de uma nova cartografia do passado e do presente. Para Holanda (2012), esse momento faz emergir uma nova arquitetura de museus, novas políticas de exibição e, junto com elas, a transformação da figura do curador que, de guardião de acervos passa a mobilizador de acervos.

Os museus tonam-se, assim, espaço de trânsito, de encontros virtuais, de celebração e afirmação de passados, memórias e anseios de futuro, cenário para entretenimento mais do que de ação didática, incentivando a partilha de lugares, pessoas, objetos, narrativas e identidades.

Pensar, por exemplo, o patrimônio e a memória da população afro-brasileira no contexto das relações raciais de hoje, na Bahia e no Brasil é, sem sombra de dúvida, um desafio e uma aposta na possibilidade de legar às futuras gerações de afrodescendentes, grande parte da produção intelectual e material da cultura negra na travessia para o Novo Mundo.

O rápido avanço das atuais tecnologias digitais tem nos possibilitado colocar em perspectiva temas caros a esse projeto - raça, hierarquias, geopolítica do saber, intangibilidade do patrimônio - assim como tem estimulado novas sensibilidades políticas, culturais, econômicas, éticas e estéticas para as áreas da museologia, da gestão e das estratégias geopolíticas de preservação da memória. Inequivocamente, essas tecnologias digitais, quando aplicadas aos museus, vêm facilitando as tarefas do trabalho de inventariação, catalogação e gestão das

possui conta neste portal. (http://www.flickr.com/photos/rbpdesigner/8693175467)

10 O site foi criado em 2008, mas só foi ao ar em março de 2010. Criado pelo americano Ben Silbermann que usou de seu hábito de colecionar coisas para criar o Pinterest. É uma rede social de compartilhamento de fotografias que funciona como galerias de imagens com a opção de exposição temática. É possível encontrar aí uma galeria com acervos de museus brasileiros. http://pinterest.com/moyarte/ museus-brasileiros-acervo/ 
coleções, assim como a difusão desse tipo de trabalho, revolucionando a forma como as instituições e os indivíduos ligados ao tema das politicas afirmativas e relações raciais vêm se comunicando, revelando-se uma ferramenta ágil e dinâmica para o desenvolvimento de diferentes projetos e ações no âmbito do patrimônio cultural e para a concepção e difusão de conteúdos culturais e pedagógicos.

Tome-se como exemplo a disponibilização digital pelo MUSEU AFRODIGITAL" da documentação relativa a passagem de Ruth Landes e Lorenzo Turner na Bahia que tem sido reivindicada por diferentes grupos e lideranças no campo da antropologia e do patrimônio - amplamente procurada por estudantes, curiosos e pesquisadores - bem como o farto acervo coletado por Melville Herskovits, sugerem que estamos diante do que se pode chamar de museum-frictions, isto é, um campo tensivo, político em que as representações sobre o passado da comunidade afrodescendente - brasileira e Africana - vivem numa eterna tensão entre depender da autorização do olhar especializado e legitimado do intelectual ou do museólogo e a busca pela sua autonomia representacional.

Nesse sentido, o MUSEU AFRODIGITAL da Universidade Federal da Bahia (projeto que é parte de uma rede de pesquisa envolvendo a Bahia, Maranhão, Pernambuco e Rio de Janeiro) está assentado na perspectiva de reinventar práticas discursivas e de sentido no tocante aos modos de se fazer etnografia e no trato com a memória dos (sobre)viventes do Atlântico Negro e suas gerações, organizado em três pilares : generosidade digital, isto é, a ideia de um museu construído a partir de doações e da participação popular; repatriação digital, ou seja incentivo a que os arquivos retornem a seus locais de origem e reflexão sobre a memória das populações subalternizadas.

Hoje, o Museu Digital é parte de uma rede internacional de museus digitais em que cada museu dessa rede é também um ponto de partida, uma parada, uma mirada, um ponto de encontro para estudiosos, anônimos, pesquisadores, colecionadores, estudantes ou apenas curiosos no tema da africanidade e afrodescendencia.

A estratégia de indexação adotada está pautada nos padrões internacionais para registro de metadados como já o fazem as instituições físicas, museus, arquivos e bibliotecas ao redor do mundo.A ideia é criar uma linguagem comum que permita a livre circulação e o intercâmbio de registros documentais entre pessoas e instituições em diferentes partes do mundo.

As universidades parceiras dessa rede já disponibilizam online coleções de documentos, fotografias, registros sonoros e vídeos que traçam uma cartografia de nossa paisagem histórica, política e atenta aos grandes temas que nos articula enquanto pesquisadores interessados no tema da memória e nas disputas por elas.

Em nossa busca - um pouco ao modo de Julio Verne - temos criatividade, mas tecnologia pobre. Entretanto, também como Julio Verne, não deixamos de sonhar. Queremos um Museu digital que articule novas práticas sociais às novas formas de viver e de estar no mundo.

I I O Museu AfroDigital objetiva intercambiar e digitalizar documentação e pesquisa sobre a diáspora africana, os estudos africanos e as relaçoes etnicorraciais no Brasil , disseminando a informação sob a licença Creative Commons, isto é, todo a documentação é de uso aberto e gratuito, sem fins comerciais. http:// www.museuafrodigital.ufba.br 
Memórias, mobilidade e disputa

Houve um tempo em que o deslocamento, a mobilidade dos objetos e artefatos era, em geral, resultado de atos de pirataria, saque, pilhagem e roubo qualificado.

Atos de pirataria eram praticados por tripulantes de navios sem bandeira, em alto-mar, contra propriedades ou pessoas, numa época em que o comércio era primordialmente realizado por vias marítimas. Eram homens que não se submetiam a qualquer tipo de lei; saqueavam embarcações de mercadores e percorriam as rotas comerciais em busca de objetos de valor. Eram vistos como mercenários, assassinos, párias da sociedade.

O mundo mudou e as formas de vender e comprar também mudaram. A mobilidade e o deslocamento de objetos em seus representantes digitais nos dias atuais representam uma nova ética em favor da livre circulação de bits. $\mathrm{Na}$ prática, isto significa trabalhar sob um sistema de três pilares: colaboração, conhecimento e liberdade.

A portabilidade das ferramentas de produção, transmissão e representação de conteúdo simplificaram processos, antes impensáveis ou muito caros, possibilitando que diferentes expressões artísticas sejam vistas e acessadas rapidamente pelos dispositivos de comunicação virtual ao redor do mundo. São as chamadas mídias locativas. Elas permitem mapear e georreferenciar a produção intelectual, histórica, arqueológica, sugerindo outras formas de recriar a memória coletiva sem a necessidade da pilhagem e da violência colonial.

Veja, por exemplo, a tecnologia do Google Maps que permite agregar a um mapa genérico características locativas e particulares a um indivíduo ou coletivo, como fotos, sons e vídeos, transformando a cidade, rua, ou outros espaços em lugares.

Nossa compreensão é de que as tecnologias baseadas em localização e mobilidade implicam em modos específicos de mediação, induzindo novas práticas no âmbito museal, redefinindo a compreensão de lugar, agregando, consequentemente, novas significações ao espaço do museu e ao lugar da memória. As mídias locativas atuam no espaço dos museus digitais a partir de seis grandes modos de mediação: os modos de escuta dos grupos sociais, de escrita, de representação da memória, do aspecto lúdico-pedagógico, da visibilidade e do acesso.

Em sua obra $A$ invenção do Cotidiano, o historiador Michel de Certeau apresenta uma distinção peculiar entre lugar e espaço ao abordar a questão da mobilidade que hoje se encontra presente em diversas experiências artísticas. Em sua visão, espaço é um lugar animado, um lugar praticado por um deslocamento. Sem a mobilidade, não haveria espaço, haveria apenas lugares estáticos, fixos e imutáveis.

A mobilidade transforma os lugares em locais de passagem e de trânsito, efêmeros e provisórios, em que se deslocar é antes atravessar o espaço e suas próprias fronteiras.

Estas novas redes semântico-digitais criam um novo ambiente, um cenário onde se realizam atos sociotecnicos em dinâmicas, suportes e formatos inéditos. O que nos faz pensar em como organizar nessas coleções os processos de preservação de memórias, histórias e acervos documentais fora dos espaços tradicionais e canônicos como bibliotecas, arquivos e museus.

O farto material que hoje compõe nosso imenso patrimônio afro-diaspórico - que vem sendo ampliado com as doações de novos arquivos por meio 
de licença para digitalização e difusão digital - não é mais feito de massa, argila, cal, ferro ou bronze, é feito zero e uns (010l0l0), um código binário que nos desafia a repensar o lugar histórico, simbólico e real desses homens, mulheres e crianças negras e negros que ajudaram a (re)fundar a identidade na Diáspora.

Recuperar esse imenso acervo é mais que um dever com as políticas de ações afirmativas, é um dever como intelectuais engajados numa outra visão de mundo mais generosa e eticamente mais comprometida.

Queremos, portanto, refletir acerca das implicações éticas, étnicas e estéticas do uso das imagens dos afro-brasileiros em contextos museais, isto é, será que patrimonializar e espetacularizar populações historicamente subalternizadas tem afetado as hierarquias e o imaginário racial sobre o negro no Brasil? Entendemos que pensar as novas políticas patrimoniais pode ser a possibilidade de produzir a insurgência epistêmica como condição para descolonizar a memória e as imagens da população afro-brasileira.

O desafio fundamental dos museus digitais hoje é refletir sobre seu papel nesse mundo em constante transformação, mas que guarda também continuidades históricas, especialmente quando se trata da questão racial. Enquanto tempo e espaço são suprimidos, condensados ou subvertidos, os museus podem assumir seu lugar nesse cenário como conectores, pontes entre a memória e o esquecimento, entre o individual e o coletivo, o local e o global, entre o que se é, e o que se pretende ser. Os museus nos permitem acessar no presente a memória do passado para, a partir daí, promover perspectivas de futuro.

Ainda que a maior parte dos atuais museus existentes na rede web sejam apenas portais construídos e mantidos exclusivamente para reunir e expor obras-de-arte geradas, originalmente, por processos de síntese, ou, por meio de cópias digitais, as características constitutivas da Internet lhes conferem um outro desenho propiciando a conectividade e ampliando as possibilidades de interação do usuário-visitante com a obra, com o criador, com o curador eliminando empecilhos espaciais e temporais, ao tempo em que também impõe restrições de ordem cognitiva e tecnológica, assim como barreiras linguísticas.

Os arquivos públicos e bibliotecas que abrigam essa documentação, tanto no Brasil quanto em África estão em péssimo estado de conservação e os centros de documentação a respeito não dispõem de pessoal nem infraestrutura para assegurar a eficaz conservação do acervo. Sabemos que lidar com o tema do racismo e das hierarquias raciais nesse país tem sido um desafio para os cientistas sociais, ainda reféns do imaginário social da democracia racial. $O$ que torna esse projeto de Museu Digital para pensar a memória Africana e a diáspora um investimento necessário para revirar nossa história e assumir nossa memória da dor, mas também das resistências. Dito de outra forma, implica em dar visibilidade à população afro-brasileira, nos interrogando sobre qual a melhor forma de cuidar de sua memória e de seu patrimônio cultural material e imaterial.

É possível perceber o alcance notável de cada postagem/depoimento feita na página do Museu no Facebook (fanpage). O alcance diário e o impacto sobre os usuários podem chegar a 600 pessoas diariamente. Isso é muito mais que a maior parte dos museus físicos consegue alcançar com exposições, em geral, dispendiosas e pouco visitadas.

A média de visualizações de cada post tem sido de aproximadamente 150 pessoas. Se calculássemos por mês, é como se uma mesma foto, arquivo ou documento fosse acessada por dia 04 vezes por usuários distintos. As coleções do acervo de F. Frazier, Lorenzo Turner e Ruth Landes estão mensalmente entre 
as mais acessadas, seja através da fanpage no Facebook, seja através do site do Museu.

Refletir sobre o conceito de Identidade, Africanidade e Afrodescendência perpetuada através da memória, agora atualizada pelos registros imagéticos e audiovisuais implica em reconhecer e investigar as consequências e os impactos da preservação da memória e do patrimônio dos povos Africanos difundidos através de processos informáticos e hipermidiáticos; em outras palavras, pretende-se aqui chegar àquilo a que Walter Mignolo (2000) chama de uma crítica da modernidade baseada em experiências geopolíticas e memórias da colonialidade.

Também esses - já não tão - novos Museus Digitais trazem outros desafios para aqueles que, como nós, estão acostumados ao trato com documentos e memória: como fica a questão da propriedade intelectual? Do direito digital? Da custódia dos originais? Como proceder à repatriação digital, ou seja, o incentivo a que os arquivos retornem a seus locais de origem? Como assegurar não somente sua preservação, mas desenvolver dispositivos para visitação que articulem a experiência tátil, emocional, lúdica e intelectiva sem perder a fruição estética? Como incentivar o desenvolvimento de plataformas e softwares específicos para gestão de patrimônio museológico em ambientes open access e livre?

Como esperar que esses museus digitais ajudem a, não apenas objetivar a memória, mas estimule a criação de redes interinstitucionais e inter-geracionais para também subjetivar a memória de grupos historicamente ausentes dos lugares de legitimação da memória?

Como fazer para que esses portais sejam mais que meros catálogos eletrônicos, servindo de mural para promover jogos políticos sem fabricar efeitos de ressonância nas políticas de memória de grupos subalternizados como aqueles da diáspora do Atlântico negro, por exemplo? Como se vê, há ainda muito mais perguntas que respostas.

É nesse contexto e espírito que compreendo a existência do MUSEU AFRODIGITAL: questionando os modos como a política patrimonial vem se desenrolando no país, propondo uma espécie de gestão coletiva da memória através da cooperação de plataformas e tecnologias digitais, mas também e, sobretudo, da partilha de saberes outros que contemplam e fundam uma nova engenharia de laços sociais, atravessada pelas noções de solidariedade na partilha dos acervos, ética no trato com a documentação de povos ex-colonizados, estímulo à autonomia e gestão de recursos financeiros e intelectuais, afirmação de um protocolo de intenções que oriente o trabalho do museu digital em torno de princípios estruturantes para seu bom funcionamento, isto é: acesso aberto, público e gratuito ao material digitalizado; compartilhamento das informações e da tecnologia utilizada; uso de padrões de captura e tratamento da imagem; definição de padrões na arquitetura informacional para coleta e indexação dentro dos repositórios, facilitando a rápida recuperação da informação; adoção de padrões de preservação digital.

A pergunta que faço agora é: será possível que esse tratamento etnográfico assentado na perspectiva de um projeto expográfico digital, buscando respeitar o caráter histórico, etnográfico e patrimonial da obra de R.Landes e L. Turner pode induzir um novo diálogo com as comunidades afetadas por este trabalho? Será possível questionar o regime de verdade imposto em uma visão tradicional da historiografia que imputa aos documentos um caráter de testemunhalidade? Será que esse modo de tratar a documentação abrindo o canal de 
comunicação com a sociedade em volta dos arquivos pode ajudar a criar novas narrativas sobre o passado?

E de que passado estamos a falar? O passado vintage vendido nas lojas de souvenires em museus espalhados mundo a fora? $O$ passado apresentado como imã de geladeira expressando o vazio a-histórico e a recusa ao fluxo do tempo? O passado expresso nas recriações de navios-negreiros a tentar expulsar o problema da consciência histórica e o passado que não gostaríamos de lembrar? O passado fantasmático travestido de tendência de moda em cores e formatos que podem ser levados na bagagem de mão no retorno das férias?

Nesse tempo em que a exacerbação da memória parece ter se tornado a chave para compreender/interrogar nossa história e nosso passado, convém lembrar a advertência de Jelin quando diz que:

\begin{abstract}
Cabe establecer un hecho básico. En cualquier momento y lugar, es imposible encontrar una memoria, una visión y una interpretación únicas del pasado, compartidas por toda una sociedade. (...)Siempre habrá otras historias, otras memorias e interpretaciones alternativas en la resistência, en el mundo privado, em las Catacumbas. Hay una lucha política activa acerca del sentido de lo ocurrido, pero también acerca del sentido de la memoria misma. El espacio de la memoria es entonces un espacio de lucha política, y no pocas veces esta lucha es concebida en términos de la lucha (contra el olvido): recordar para no repetir.( 2002 :06)
\end{abstract}

Para a autora, a luta da memória contra o esquecimento (contra o silêncio) esconde uma disputa entre memórias rivais (cada uma com seus próprios esquecimentos). Trata-se na verdade, de memória contra memória.

\title{
Breves Considerações Sobre o Futuro Do Passado
}

A memória pode e deve ser entendida como elemento importante para a análise do pensamento social, ora como agente agregador (memória da ancestralidade africana) ora como empecilho à formação de uma nação moderna e mestiça como pensava, p. exemplo, G. Freyre e S. Romero.

Se a noção de raça se construiu como um "problema brasileiro", a memória como artifício discursivo e político ajuda(ou) a fabricar as múltiplas interpretações sobre o Brasil, operando em paralelo e ao lado de categorias como etnia, nação, território, identidade, auxiliando na difícil tarefa de ancorar os fatos reais ou esquecidos. Talvez, um modo plausível de compreender essa afirmação seja concordar com o escritor G. Garcia Marquez (2005) ${ }^{12}$ Minha única explicação é que da mesma forma que os fatos reais são esquecidos, também alguns que nunca aconteceram podem estar na lembrança como se tivessem acontecido.

Nesse sentido, me aproximo intelectualmente do pensamento de Furtado (2003) quando diz:

a escrita da memória concilia o trabalho de luto e a posse da origem, as verticais da perda e as horizontais da linhagem, o exílio da história e o mito do paraíso perdido, o destino nômade e o retorno ao locus amoenus de onde nunca saímos. (2003:21)

12 In: Memórias de minhas putas tristes. RJ: Ed. Record. 2005 
Assim também, Cuperschmid em um texto seminal acerca das narrativas produzidas sobre Auschwitz em um capítulo intitulado Imperativo da memória nos diz que o trabalho da memória é indissociável da vida social.

A memória é uma espécie de 'categoria afetiva' em nossa relação com o passado e coma história. Ou, como diz Selligman-Silva, memória só existe no plural. Nesse sentido, a guerra de memórias pode ser 0 resultado de nossa luta frequente entre o desejo de representar o passado (à nossa imagem e conveniência) e a necessidade de domesticar o futuro enquadrando o presente. (201I :122)

Autores como Pierre Nora e Maurice Halbwachs dedicaram parte de seu trabalho a desvendar as entranhas e as porosidades dos chamados "lugares de memória" que permitiu a Jacques Le Goff empreender um pequeno tratado em seu verbete sobre a "Memória" escrito para a Enciclopédia Einaudi'13 onde nos diz:

[há] os lugares topográficos, como os arquivos, as bibliotecas e os museus; lugares monumentais como os cemitérios e arquiteturas; lugares simbólicos como as comemorações, as peregrinações, os aniversários ou os emblemas; lugares funcionais, como os manuais, as autobiografias ou as associações (1990:473)

Mas há, por fim, aquilo que poderíamos chamar de 'lugares por trás dos lugares', é aqui que nos encontramos com as forças e a resistência dos que não se deixaram abater, dominar, dos povos que ergueram nações exiladas de sua própria terra, de memórias ainda não reveladas, outras desejando ser esquecidas, de monumentos destruídos e estéticas reinventadas; corpos-sujeitos-assujeitados-lugares-discursos-memórias. Luta pelo direito a lembrar e pelo direito de esquecer. Batalha de signos esgarçados à beira de oceanos; guerra sem vencedores num campo minado, devastado por restos de histórias. Sobras, sombras, exílios, asilos, roupas, rotas, palavras, lavradas no fogo da memória que arde em ruínas.

Referências Bibliográficas

BENJAMIN,W.Documentos de cultura. documentos de barbárie :escritos escoIhidos I . seleção e apresentação Willi Bolle ; trad. Celeste H.M. Ribeiro de Sousa ... I et al. I. - São Paulo: Cultrix : Editora da Universidade de São Paulo. 1986 CUPERSCHMID, Ethel Mizrahy. MUITO ALÉM DAS CINZAS: Narrativas de Auschwitz. SP. Ed. Blucher, $201 \mathrm{I}$.

DE CERTEAU, M. História e Psicanálise: entre ciência e ficção. Belo Horizonte: Autêntica Editora, 20II.

FURTADO, Fernando Fábio Fiorese. Murilo na cidade: os horizontes portáteis do mito. Blumenau, Edifurb, 2003

GUIMARÃES, Cesar. As imagens dos Guarani e Kaiowá resistem.In:BRANDÃO,A. A sobrevivência das imagens. Campinas, SP. Papirus, 20I5. Pag. 35-48.

GUATTARI, F. Caosmose: um novo paradigma estético. Tradução Ana Lúcia de

I3 LE GOFF, Jacques “Memória” in Enciclopédia Einaudi, Memória - História (trad.) Lisboa, Imprensa Nacional/Casa da Moeda, 1990, vol.I, p.46. 
Oliveira e Lúcia Cláudia Leão. Rio de Janeiro: Ed. 34, 1992.

HOLANDA, Heloisa B. De que se fala quando se fala de memória. Disponivel em http://www.heloisabuarquedehollanda.com.br. Atualizado em 09/09/20I2 JELIN, Elizabeth $O$ trabalho de memória. Madrid: Siglo XXI, 2002

MENESES, Ulpiano T. Bezerra de . O museu e o problema do conhecimento. In: IV Seminário sobre Museus-casas: Pesquisa e Documentação, 2002, Rio de Janeiro. Anais do IV Seminário sobre Museus-casas: Pesquisa e Documentação. Rio de Janeiro : Fundação Casa de Rui Barbosa, 2000. P. I7-48.

QUIJANO,Anibal. Colonialidade do poder, eurocentrismo e América Latina. En:A colonialidade do saber: eurocentrismo e ciências sociais. Perspectivas latino-americanas. Edgardo Lander (org). Colección Sur Sur, CLACSO, Ciudad Autónoma de Buenos Aires, Argentina. setembro 2005.

SCHEINER, Tereza. Museologia ou Patrimoniologia: reflexões. In: Museu e Museologia: Interfaces e Perspectivas/Museu de Astronomia e Ciências Afins Organização de: Marcus Granato, Claudia Penha dos Santos e Maria Lucia de N. M. Loureiro .- Rio de Janeiro : MAST, 2009

SILVA, Jamile Borges da. Museus on-line: longevidade e conservação digital da memória In: A política do intangível: museus e patrimônios em nova perspectiva / Livio Sansone (Organizador). - Salvador: Edufba, 20 I2. p.: 263-276

TOTA, Anna Lisa. A Sociologia da Arte. Do Museu Tradicional à Arte Multimédia. Lisboa: Editorial Estampa, Lda, 2000. 